\title{
Community expectations and motivations in entomological research activities for the development of innovative malaria vector control tools: Target Malaria as a case study in Bana, Western Burkina Faso
}

Nourou Barry ( $\square$ nurdinebarry@gmail.com )

Patrice Toé

Université Nazi BONI, Bobo-Dioulasso

Lea Pare/Toe

Institut de Recherche en Sciences de la Santé

Javier Lezaun

Institute for Science, Innovation and Society, University of Oxford

Mouhamed Drabo

Imperial College London Department of Life Sciences

Roch Dabiré

Institut de Recherche en Sciences de la Santé

Abdoulaye Diabate

Institut de Recherche de la Santé

\section{Research}

Keywords: public engagement, entomological research activities, malaria, Target Malaria, Bana, Burkina Faso

Posted Date: January 1st, 2020

DOI: https://doi.org/10.21203/rs.2.19777/v1

License: (c) (i) This work is licensed under a Creative Commons Attribution 4.0 International License.

Read Full License

Version of Record: A version of this preprint was published at Malaria Journal on June 5th, 2020. See the published version at https://doi.org/10.1186/s12936-020-03277-7. 


\section{Abstract}

\section{Background}

Many field entomology research projects involve local communities in mosquito-collection activities. Since 2012, Target Malaria, a not-for-profit research consortium, has been working with community members in various studies of mosquito collection, release and recapture in the village of Bana, in Western Burkina Faso. Target Malaria's long-term goal is to develop innovative solutions to combat malaria in Africa with the help of mosquito modification technologies. Since the start of the project, members of local communities have shown interest in playing an active role in the implementation of the project's research activities, but their actual motivations for such an interest remain under-investigated. This study therefore aimed to examine the factors that motivate the local community to contribute to the implementation of Target Malaria's activities in the village of Bana.

\section{Methods}

A qualitative approach was used to examine the factors motivating the local community to assist in the implementation of Target Malaria's entomological research activities in Bana. 85 individual in-depth and semi-structured interviews were conducted, followed by interviews with three focus groups, one with youths who had participated in mosquito collections and two with men and women from the village. All data collected were fully transcribed, processed, and submitted for thematic content analysis.

\section{Results}

Data showed that the willingness of local community members to participate in the entomological research activities of Target Malaria was informed by a wide range of motivational factors. Although the actors interviewed expressed their motivations under different semantic registers, the data showed a degree of consistency between different motivations advanced. These similarities enabled us to classify all of the motivational factors under 5 distinct categories: (a) assist in field research, (b) contribute to a better future, (c) acquire knowledge, (d) earn financial compensation, and (e) gain social prestige.

\section{Conclusion}

These varying motivations reflected fundamentally different personal and collective perceptions about the participation process. In addition, this study shows that the interest of research on participation is a useful part of understanding public perceptions.

\section{Background}

Despite the efforts made in the control of malaria over the last decades, progress in many regions seems to be coming to a halt [1]. The growth of resistance to mainstay insecticides constitutes the most serious 
threat to sustainable success with existing tools [2-4]. Different species of Anopheles mosquitoes have shown an increasing resistance to multiple pesticides [5,6]. A recent World malaria report $[1,7]$ indicates that malaria mortality is actually increasing in several countries, including Burkina Faso.

There is as a result a growing emphasis on the development of new tools or approaches, and on the improvement of integrated control strategies. This includes the possible use of genetically-modified malaria vectors to achieve population suppression or trait replacement [8,9] as part of an integrated malaria control strategy $[10,11]$.

Target Malaria is an example of this strategy. In the long-term, this collaborative consortium seeks to use genetic modification of specific vector strains to suppress their ability to reproduce $[12,13]$. By using gene drive constructs, the project seeks to create modified strains of Anopheles mosquitoes that will be capable of transmitting this trait to the vast majority of its offspring, thus allowing it to quickly spread through the population [14]. This technology could be a key complementary tool for malaria eradication.

In Africa, Target Malaria operates in four countries: Mali, Uganda, Ghana and Burkina Faso. Target Malaria's technology is currently being developed in three phases: self-limiting sterile males, self-limiting male bias, and self-sustaining male bias or self-sustaining target knock-out. Each of these phases then further entails different stages of technological development. The current paper focuses on work conducted during the period of baseline entomological field research, prior to the release of any genetically modified mosquitoes.

In Western Burkina Faso, these field entomological activities have been underway since July 2012. They include Human Landing Catch sampling of mosquito populations, location and collection of swarms, egg surveys, insecticide spraying catch [15], as well as mark-release-recapture experiments [16,17]. The entomological activities conducted in the field require close involvement of members of the local community. In addition to their participation in entomological work, communities were also engaged through regular group interactions, discussions and dialogue sessions, and general meetings and individual dialogues regarding the project and its objectives. The motivations and aims of Target Malaria's entomological activities were widely explained, including the link between ongoing mosquito collections and the ultimate goal of developing genetically modified mosquitoes to control malaria vectors.

The overarching aim of community engagement activities was to obtain a social license to operate in the villages in question [18-20]. Indeed, as part of the Target Malaria project, local community members were engaged at the consultative, functional, interactive, and/or mobilisational levels corresponding to the four levels of the participatory scale [21-23].

Community participation is broadly considered essential for attaining an effective control of disease vectors [24]. Multiple studies attest to the role played by local communities in the control of those diseases [25-29]. Unfortunately, these studies do not provide information on the factors that motivate local communities to get involved in mosquito control programmes. Thus, the issue of community 
motivation in such context remains under-investigated. In Burkina Faso in particular, there is generally very little information on the reasons that motivate local communities to participate or not in entomological research programmes. The scant research information available on community participation in health programmes is limited on the theoretical and practical aspects of the local actors' participation [30-32] or the ethical aspects [33]. Where data are available, they generally pertain to clinical research [34] where a direct personal benefit is often assumed. We therefore lack a good enough understanding of the reasons that bring people to participate in entomological research projects for vector control. Target Malaria offers a good opportunity to expand our knowledge of these factors, as it involves long-term baseline field entomological work, as well as the potential release of genetically modified mosquitoes for research purposes. Target Malaria and its technology have generated opposition and criticism, and that the work of Target Malaria in Burkina and elsewhere has also attracted some national and international critics. However, it is still important to understand what are the motivations of those people who choose voluntarily to collaborate with this project. It thus allows us to study the complex motivations that people have to participate in mosquito collection activities, and in entomological research activities supporting novel methods of malaria control more generally.

\section{Methods}

\section{Study site}

This study was conducted in the village of Bana, located in Western Burkina Faso, approximately $20 \mathrm{~km}$ from Bobo-Dioulasso (Figure 1). In 2012, the population of Bana was estimated to be approximately 982 inhabitants, 498 men and 484 women [35]. Bana has two main inhabited areas, Bana Centre and Bana Market, separated by a small river (usually dry during the dry season). Bana Centre is the principal agglomeration and includes the village administration; Bana Market is the economic centre of the village and hosts a busy weekly market. The whole village is a loose cluster of about 130 compounds (local census, October 2014). Each compound is a family unit consisting of between two and ten houses, generally made of mud. The largest ethnic groups are the Bobo, Dioula, Mossi, Fulani, and Sambla. The Bobo ethnic group is the indigenous group in the area. The most widely spoken language is Dioula. Similar to most rural areas in Burkina Faso, Bana's economy is essentially based on subsistence agriculture [36].

\section{Approach and study population}

This was a qualitative study based on an anthropological approach in which the researcher displayed an active and participatory posture. In this approach, emphasis was placed on the stakeholders' perception of their situations, what sense they made of the situations, and their interactions through these situations. As Olivier de Sardan has noted [37], anthropology produces reports and interpretations based directly on the context and coherence of all available facts. The empirical surveys conducted as part of this research enabled us to gather experiential data and relatively detailed statements from local community members engaged in Target Malaria's ongoing activities in the area. 
The study population comprise all of the residents of Bana who have played an active role in the implementation of Target Malaria activities. These actors included youth volunteers participating in various mosquito-collection techniques, village leaders (including traditional leaders such as chief of village, elders, notables; and formal leaders such as members of the village's development council ('Conseil Villageois de Développement' or CVD), as well as all members of the village who have granted access to their households, houses, and rooms for mosquito collection.

\section{Data-collection techniques and tools}

This study was conducted by members of the team working for Target Malaria in Burkina Faso. The data were collected between October 2017 to January 2018, following detailed semi-directive interviews and focus groups discussions. Out of a total of 130 households in Bana, all participating in the entomological activities of the project, 80 were visited and surveyed and the survey topics focused on how communities perceive Target Malaria and the reasons for their participation in the project activities. Twenty of these households were selected because they were the ones in which entomological activities (indoor pyrethroid spray catches, swarm collection, and human landing catches) were carried out on a monthly basis. The remaining 60 households were randomly selected. A total of 85 in-depth individual interviews were conducted with members of the local community. Furthermore, three focus groups were conducted, one with the youth volunteers (involved in mosquito collection), and one each with male and female residents of Bana. All participants in the focus group discussions had participated in Target Malaria, primarily by granting access to their premises for project activities. The discussions were held in the Dioula language and recorded with a Dictaphone.

\section{Data processing and analysis}

The data were processed and tabulated with the QDA Miner Lite software, a multi-dimensional database and quality data-processing software used to process large amounts of textual data. There was a thorough qualitative analysis of the data content [38] complying with all of the key stages mentioned about the topic [39]. The interpretation of the results was primarily based on these data, but relied also on comparison with other surveys and focus group discussions conducted on similar topics from other projects in African countries [31,40-43].

\section{Results}

Our data shows that the participation of local communities in the implementation of Target Malaria entomological research activities was informed by a wide range of motivations. Five key themes emerged consistently in the interviews and focus group discussions, even if individual actors often expressed them in different semantic registers. Thus, we classified the motivations into five categories: to support field research activities, to contribute to a better future, to acquire knowledge and improve skills, to enjoy financial benefits from participation in the project, and to gain social prestige.

\section{Concern for mosquito and malaria control}


The main reason why members of the Bana local community participated in mosquito-collection through Target Malaria was the desire to protect themselves against mosquito bites and malaria. All of the community actors agreed with this reason. A 35-year-old housewife said, "My husband and I have agreed for our home to be sprayed because we want to get rid of the mosquitoes in the house" (35-year-old housewife, Bana). Indoor spraying activities (Figure 2) were aimed at assessing the density of endophilic mosquitoes and their variation over time and space. They allow the determination of the numbers of blood-fed mosquitoes, the origin of the blood meals, and the level of infectivity of malaria vectors. Our data show that fear of mosquitoes and of the harm they can cause is an obvious concern in the area, and that entomological research reduced the number of mosquitoes in the households. As another woman stated: "Whenever they come to spray the house, they drive away a lot of mosquitoes. Again, we know that mosquitoes are not good. This is why l accepted to do the work. Because mosquitoes are not good." (women's focus group, Bana). Similar statements were gathered from other participants. Expressions such as "We want to get rid of mosquitoes from our homes", "We want good health", "by spraying our homes, they chase out a lot of mosquitoes" and "one day my children will be spared the disease" all highlighted the concerns that the local communities have regarding the harm caused by mosquitoes and the malaria they transmit. Thus, local communities perceived that, through its entomological research activities Target Malaria directly reduced mosquito densities in the village and this motivated residents to actively participate in them. "Mosquitoes are the ones which give us malaria; and to me, combating malaria is a good thing. As for me, I have children and I know that if malaria is controlled, one day my children will be free of this disease and that is good' (women's focus group, Bana). Despite the project's regularly messages that mosquito collections activities are not intended for vector control (the aim of mosquito collection activities is not to remove mosquitoes from a house, it does not give lasting protection and that, the team always mention the importance for the communities to keep using bednets, etc.), local communities perceive these entomological activities as protecting against mosquitoes and malaria.

\section{'Contribute to a better future' and participate in noble research: the meaning of words}

A second motivations behind the participation of Bana residents in entomological research activities is the desire to 'contribute to a better future'. This theme emerged in a variety of interviews and focus group discussions. Several interviewees considered Target Malaria an example of 'forward-looking research', in the sense that it could provide in the long term a solution for malaria. This idea is highlighted in the following statements: "As for me, I believe that we are contributing to a better future through our participation in the project. The mosquitoes which I catch myself, it's as if I was working for myself or for my children. Even if I'm not alive tomorrow, at least I might have done something for tomorrow. For example, for those of us who are farmers, if you buy cattle and tomorrow you're no more, your children can still work with the cattle. That is how this project is; we are searching for a solution to malaria to save tomorrow's people" (A 33-year-old mosquito-collecting youth, Bana). Local residents perceived that the various mosquito-collection activities in the village aimed at finding a future solution to their mosquito problem. They believed that this was a noble objective, and that by participating in the project they were doing "good" and contributing to a better future for future generations. One can assume that local 
residents were conveying messages often put forth by the researchers about the ultimate objective of their activities ("contribute to a better future," "serve tomorrow," "noble research," etc.). Several interviewees reported a sense of pride in being actively involved in this work.

\section{Mosquito collection activities: the stages of learning}

Some local residents interviewed also considered their participation in the entomological research activities as an opportunity to improve their knowledge on mosquitoes. The desire to understand mosquitoes and learn more about mosquitoes and mosquito collection techniques were identified as reasons for their participation. This category of motivation was particularly salient among mosquito collectors (Figure 3): "I came to do the work because it is a research which they are conducting. I want to learn this work. Knowing the mosquito, knowing how to catch them in order to combat malaria" (28-yearold mosquito collector for Target Malaria, Bana). Most of the interviewed youths said that their involvement in Target Malaria would allow them to acquire specific knowledge on mosquitoes and mosquito-collection techniques that would enable them to contribute in the fight against malaria. As another participant in the same focus group said, "As for me, I wanted to learn how to capture a mosquito. I know that a mosquito is small. How they are able to catch it. This way, I can also learn how the mosquito transmits the disease" (34-year-old mosquito collector for Target Malaria, Bana). Several statements were collected to identify the type of knowledge acquired by community actors. One of the mosquito collectors said this: "Thank to the project, I learned how to catch mosquitoes. And then now I can differentiate between the kinds of mosquitoes according to whether they are male or female. I know that the male is the one who has a lot of hair on his mouth, he doesn't bite. While the female has a small mouth and a long pointed beak and it is she who bites. In the evening I can identify swarms of mosquitoes, whereas in the past I thought it was dust. Concerning the night, people may wonder how to catch these little bugs, we were shown this. For the third, which is spraying, I learned how to pick them up on the sheet with a pair of pliers and put them in a box. I learned all this in the project." These comments, which are widely shared by the mosquito collectors, reflect some of the forms of knowledge acquired through participation in the project's entomological activities.

Although the participation of the village youths in the entomological activities may be perceived as a means to learn about mosquitoes and mosquito collection techniques, it sometimes obscured another motivational factor. Indeed, when they said "Do the work," "to work," or "how to work," the mosquito collectors were referring to mosquito-collection techniques (Figure 4) that they perceived as elements of a "trade" they could learn, and that could be useful for future activities in Target Malaria or in similar activities in the future. In fact, although for research purposes, this activity necessitates the availability of mosquitoes: "catch the mosquito" and "capture the mosquito". Meanwhile, the action words "to catch" or "to capture" come from a knowledge model also directed by research. This new "job" must learned. Capture at night ("Sufè minè" (Sufè = night, minè = catch) and capture during the day ("Téléfè minè" (Téléfè = day, minè = catch) required awareness, learning, and knowledge regarding mosquitoes and their environment. 
The participation in Target Malaria activities in Bana included a form of financial compensation for the local actors involved. Target Malaria included this in its research protocol submitted to the ethics committee and discussed the issue during information sessions and when seeking volunteers for research activities in the village. In this protocol, Target Malaria insisted that this was not a "remuneration" or "salary", but rather "compensation" for the time spent by local residents on research activities. Target Malaria understands remuneration as an amount paid directly to employees in exchange for their work, and it requires the establishment of a services contract. This is not the case for the activities studied in this study, which were conducted in the absence of a contractual arrangement hence the preference for the term compensation, which describes a lump sum granted to volunteers for the loss of income due to the time they invest in the project. Regardless of the terminological nuances, however, this financial compensation was a significant factor for some of the participants, especially the mosquito-collector youths, and attracted significant interest. One of those interviewed provided the following reasons: "Some of us, we are interested in this work because of the monetary reward attached to it. Something which helps us solve our petty financial problems. If someone asks me how is your work, I will tell them the mosquito-catching job is very good and that it is economically good to do this job. It is because of the money given after the work." (28-year-old mosquito collector for Target Malaria, Bana). In their statements, the local expressions used by the volunteers to qualify the financial compensation were

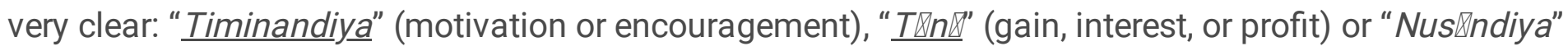
(cheerful or being happy). These expressions, specially " $T \rrbracket n \rrbracket$ ", referred to the financial resources provided by the project. This compensation serves as a direct motivation for those involved in mosquito collection.

In Bana, vegetable growing has a crucial importance as it is one of the only ways to collect revenues during the 5- to 6-month dry season and compensate for potential bad yields. Almost all of the youths do regular gardening as an income-generating activity, yet this activity is insufficient to meet their needs. This partly explains the value the attribute to income opportunities offered by Target Malaria. The observation was confirmed by statements from the other focus groups. As the mother of a mosquitocollector youth said: "The village youths are our children. We know them very well. They offer to catch the mosquitoes because they gain something like financial benefit from it." (46-year-old housewife, mother of a mosquito-capturing youth, Bana). These financial benefits acquired from their participation in Target Malaria activities have a significant socioeconomic impact on their cultivation or gardening activities. The money received from the project is used by some youth to buy for some equipment (motor pump, petrol, manpower) for their economic activities which could improve their yield.

\section{"Social prestige" and "village reputation"}

Some statements from local residents, especially village leaders, highlight the role of prestige as one of the factors motivating them to host the project. "As for me, I really understand the objectives of your project in our village... And I know that, thanks to this project, the name of the village will be projected into 
the limelight. And people all over the world will wonder where the village of Bana is located. The fact that such research is being conducted in this village is an immense motivation for us, for, in any case, it would bring immense social benefits to the village" (46-year-old village leader, Bana). This statement suggests that, in the perception of some residents, the entomological activities conducted by Target Malaria enhance the village's image, both at the national and international levels. This was explicitly stated by one of the village residents interviewed: "And, if in the meantime the project achieves the expected results and success in the work, even if we are not alive, people will say that research has been done in Bana. Bana's name will be mentioned everywhere. And as a resident of the village, I will be very proud. That's why I think it's important to get involved" (38-year-old men resident, Bana).

\section{Discussion}

This survey assessed the perceptions that Bana residents had of their participation in Target Malaria. Specifically, the study examined the factors that motivated members of the local community to become actively involved in an entomological research project. These motivational factors can be described as voluntary service, an activity to which time is allocated for the benefit of another person, group, or cause. Motivation, in this context, as some authors [44] reported, can be defined as an intra-personal need or desire that stimulates a behaviour and gives it direction. Studies on voluntary service have shown that successful participation is due to the specific motivations attached to the voluntary service $[43,45]$ and that these motivations can predict the preferences of the voluntary service in the future.

Thus, the range of motivational reasons gathered from our local actors highlight the multiple reasons that sustain public participation in entomological research work. Through their motivations, the actors interviewed became aware of their need to join the fight against malaria, to which all of them are vulnerable. In fact, the vulnerability to mosquitoes and malaria and the need to find an efficient way of managing this disease seem to be the most important motivation influencing the decision to actively engage with Target Malaria. This vulnerability affects all categories of local residents, as malaria remains a main cause of hospitalisation and mortality in rural areas of endemic countries like Burkina Faso $[7,46]$. This motivation reflects the confidence that the local communities have in Target Malaria, and in its commitment to introduce innovative methods of malaria control. Among African countries, Burkina Faso has acquired a reputation as a pioneer in the development of new methods for the control of malaria vectors, including mosquito modification technologies $[17,47,48]$. This might explain the sense of pride reported by some of the participants.

Data shows that participants often acquire useful knowledge and skills. All the local communities interviewed highlighted the opportunity to take advantage of their involvement in the project to learn or improve their knowledge. Bana inhabitants, especially youth mosquito collectors, reported the variety of skills they have learned since 2012 thank to this project. For the majority of those youth, Target Malaria is their first experience in mosquito collection. Thus, they perceived this as a real opportunity for which they are proud, especially since they intend to capitalize on this knowledge in order to use it later, beyond Target Malaria, in other similar projects requiring entomological collections. 
Some authors have shown that in most developing countries, especially in Sub-Saharan Africa, health research collaboration between actors in the north and those in the south, even though unequal and complex to some extent $[49,50]$, is perceived by each as a promising collaboration in the sense that it brings on board expertise, funds, and diverse resources to Africa [51]. According to those authors, health research projects have provided and enhanced knowledge and expertise to African countries, particularly in the health policy and planning sectors, improved hospital and laboratory infrastructure, and research institutions. Thus, these factors have enabled the identification of preventive and therapeutic interventions for the principal causes of mortality such as HIV/AIDS and malaria, among others.

Furthermore, comparing the motivations gathered from our actors to those presented by some authors in the context of biomedical research, we reached the conclusion that there were differences in the actors' motivations. For example, in malaria clinical trials several studies have examined the motivational factors provided by the participants for taking part in these trials. A research study conducted in Tanzania on the motivational factors given by mothers and guardians for authorising their children and wards to participate in some malariometric trials demonstrated that most chose to participate in these trials to access better quality health services that are often lacking in public health institutions [52]. A similar survey conducted in Malawi found that financial and material gains, such as soap, groundnut paste, orange juice, transportation money, tablecloths, mosquito nets, water basins, and iron tablets, motivated the community participation $[42,53]$. These reasons aligned with those obtained from the actors we interviewed on financial compensation or pecuniary interests desired by those who participated in the implementation of Target Malaria.

But apart from individual gain, our data show a variety of altruistic motivations, particularly the desire to contribute to a better future by participation in scientific activities with a less direct material benefit. This is the most common finding in this study. In Bana, almost all of the interviewees acknowledge that the result Target Malaria is aiming for can only be achieved in the long term. It was clearly explained that the research activities of Target Malaria will only achieve the expected result in the long term. Our data show that local communities are aware of this. But despite this, the motivation to support this research project in its experimental activities remains visible in the village of Bana. The challenge for this project could then be to think about how to maintain this motivation while knowing that the benefits of its implementation will only be visible in the long term.

\section{Study limitations}

These results provide more information of Bana residents (Western Burkina Faso) motivations and expectations in entomological research activities for the development of innovative technology for malaria control. However, since data were collected by the project team members, one would think that the respondents would give answers that would appeal to the project team. These risks were therefore minimized by the fact this study was carried out by people who were not involved in the main entomological activities. In addition, the long period of immersion of the data collector in Bana has 
created a trusted relationship with the respondents throughout the course of the interviews, resulting with limited bias.

\section{Conclusions}

This survey considered the factors motivating local communities to join in entomological research activities for malaria vector control in Western Burkina Faso. A qualitative social science methodology is used to reveal an in-depth understanding of the factors motivating those Bana residents that agree to participate in research activities sponsored by Target Malaria. Our data show multiple reasons for engagement, with different categories of actor identifying different factors for their participation. Their accounts reflect the reasons for a positive perception of research activities associated with the development of novel vector control strategies, especially the desire to build a world devoid of malaria. The in-depth analysis of these different motivational factors provided new information to complement efforts to improve and maintain an active participation of local actors in entomological research programmes.

\section{References}

1. WHO. World malaria report 2019. Geneva: World Health Organization; 2019.

2. Diabate A, Baldet T, Chandre F, Akoobeto M, Guiguemde TR, Darriet F, et al. The role of agricultural use of insecticides in resistance to pyrethroids in Anopheles gambiae s.I. in Burkina Faso. Am J Trop Med Hyg. 2002;67:617-22.

3. Tripet F, Wright J, Cornel A, Fofana A, Mcabee R, Meneses C, et al. Longitudinal survey of knockdown resistance to pyrethroid (KDR) in Mali, West Africa, and evidence of its emergence in the Bamako form of Anopheles Gambiae S.S. Am J Trop Med Hyg. 2007;76:81-7.

4. Dabiré KR, Baldet T, Diabaté A, Dia I, Costantini C, Cohuet A, et al. Anopheles funestus (Diptera: Culicidae) in a Humid Savannah Area of Western Burkina Faso: Bionomics, Insecticide Resistance Status, and Role in Malaria Transmission. J Med Entomol. 2007;44:990-7.

5. Balabanidou V, Kefi M, Aivaliotis M, Koidou V, Girotti JR, Mijailovsky SJ, et al. Mosquitoes cloak their legs to resist insecticides. Proceedings Biol Sci [Internet]. 2019/07/17. The Royal Society; 2019;286:20191091. Available from: https://www.ncbi.nlm.nih.gov/pubmed/31311476

6. Killeen GF, Ranson $\mathrm{H}$. Insecticide-resistant malaria vectors must be tackled. Lancet (London, England) [Internet]. Elsevier; 2018 [cited 2019 Feb 20];391:1551-2. Available from: http://www.ncbi.nlm.nih.gov/pubmed/29655495

7. WHO. World malaria report 2018. Geneva: World Health Organization; 2018.

8. Burt A. Heritable strategies for controlling insect vectors of disease. Phil Trans R Soc B. 2014;369.

9. Alphey L. Genetic Control of Mosquitoes. Annu Rev Entomol. 2014;59:pp 205-224.

10. Raghavendra K, Barik TK, Reddy BPN, Sharma P, Dash AP. Malaria vector control: from past to future. Parasitol Res [Internet]. 2011;108:757-79. Available from: https://doi.org/10.1007/s00436-010- 
2232-0

11. Diabate A, Tripet F. Targeting male mosquito mating behaviour for malaria control. Parasit Vectors [Internet]. 2015;8:347. Available from: https://doi.org/10.1186/s13071-015-0961-8

12. Burt A. Site-specific selfish genes as tools for the control and genetic engineering of natural populations. Proc R Soc London Ser B Biol Sci. 2003;270.

13. Burt A, Koufopanou V. Homing endonuclease genes: the rise and fall and rise again of a selfish element. Curr Opin Genet Dev. Elsevier Current Trends; 2004;14:609-15.

14. Burt A, Coulibaly M, Crisanti A, Diabate A, Kayondo JK. Gene drive to reduce malaria transmission in sub-Saharan Africa. J Responsible Innov [Internet]. Routledge; 2018 [cited 2019 Feb 3];5:S66-80. Available from: https://www.tandfonline.com/doi/full/10.1080/23299460.2017.1419410

15. Epopa PS, Collins CM, North A, Millogo AA, Benedict MQ, Tripet F, et al. Seasonal malaria vector and transmission dynamics in western Burkina Faso. Malar J [Internet]. 2019;18:113. Available from: https://doi.org/10.1186/s12936-019-2747-5

16. Epopa PS, Millogo AA, Collins CM, North A, Tripet F, Benedict MQ, et al. The use of sequential markrelease-recapture experiments to estimate population size, survival and dispersal of male mosquitoes of the Anopheles gambiae complex in Bana, a west African humid savannah village. Parasit Vectors. 2017;10:376.

17. Swetlitz I. A Revolutionary Genetic Experiment is Planned for a West African Village - If Residents Agree A gene drive bid aims to eliminate malaria. STAT Med Biotech [Internet]. 2017; Available from: https://www.scientificamerican.com/article/a-revolutionary-genetic-experiment-is-planned-for-a-westafrican-village-if-residents-agree/

18. Bartumeus F, Costa GB, Eritja R, Kelly AH, Finda M, Lezaun J, et al. Sustainable innovation in vector control requires strong partnerships with communities. Scarpino S V., editor. PLoS Negl Trop Dis [Internet]. Public Library of Science; 2019 [cited 2019 Jun 3];13:e0007204. Available from: http://dx.plos.org/10.1371/journal.pntd.0007204

19. Hartley S, Thizy D, Ledingham K, Coulibaly M, Diabaté A, Dicko B, et al. Knowledge engagement in gene drive research for malaria control. Bonizzoni M, editor. PLoS Negl Trop Dis [Internet]. Public Library of Science; 2019 [cited 2019 Jun 3];13:e0007233. Available from: http://dx.plos.org/10.1371/journal.pntd.0007233

20. Thizy D, Emerson C, Gibbs J, Hartley S, Kapiriri L, Lavery J, et al. Guidance on stakeholder engagement practices to inform the development of area-wide vector control methods. Matovu $E$, editor. PLoS Negl Trop Dis [Internet]. Public Library of Science; 2019 [cited 2019 Jun 3];13:e0007286. Available from: http://dx.plos.org/10.1371/journal.pntd.0007286

21. CDC/ATSDR. Principles of community engagement. Centers Dis Control Prev. 1997;13.

22. Koelen M, Van Den Ban A. Health education and health promotion. Wageningen Academic; 2004.

23. Jacobs $\mathrm{G}$. Imagining the flowers, but working the rich and heavy clay: participation and empowerment in action research for health. Educ Action Res. 2006;14:569-81. 
24. Toledo ME, Vanlerberghe V, Baly A, Ceballos E, Valdes L, Searret M, et al. Towards active community participation in dengue vector control: results from action research in Santiago de Cuba, Cuba. Trans R Soc Trop Med Hyg [Internet]. 2007;101:56-63. Available from: https://doi.org/10.1016/j.trstmh.2006.03.006

25. Soedarmo SP. Community Participation in The Control and Prevention of DHF in Indonesia. Trop Med. 1993;35:p315-324.

26. Sawadogo SP, Niang A, Bilgo E, Millogo A, Maïga H, Dabire RK, et al. Targeting male mosquito swarms to control malaria vector density. PLoS One. 2017;12:e0173273.

27. Phanthumachinda B, Phanurai P, Samutrapongse W, Charoensook O. Studies on community participation in Aedes aegypti control at Phanus Nikhom district, Chonburi province, Thailand. Mosq Borne Dis Bull. 1985;2:1-8.

28. Gubler DJ, Clark GG. Community involvement in the control of Aedes aegypti. Acta Trop [Internet]. Elsevier; 1996 [cited 2019 Oct 8];61:169-79. Available from: https://www.sciencedirect.com/science/article/abs/pii/0001706X9500103L

29. Kaindoa EW, Ngowo HS, Limwagu AJ, Tchouakui M, Hape E, Abbasi S, et al. Swarms of the malaria vector Anopheles funestus in Tanzania. Malar J. 2019;18:29.

30. Sarker M, Sanou A, Snow R, Ganame J, Gondos A. Determinants of HIV counselling and testing participation in a Prevention of Mother-to-Child Transmission programme in rural Burkina Faso. Trop Med Int Heal. 2007;12:1475-83.

31. Desclaux A, Kouanda S, Obermeyer CM. Stakeholders' participation in operational research on HIV care: insights from Burkina Faso. AIDS. 2010;24:p S79-S85.

32. McConville JR, Kain J-H, Kvarnström E, Ulrich L. Participation in sanitation planning in Burkina Faso: theory and practice. J Water, Sanit Hyg Dev. 2014;4:304-12.

33. Hunt MR, Gogognon P, Ridde V. Ethical considerations related to participation and partnership: an investigation of stakeholders' perceptions of an action-research project on user fee removal for the poorest in Burkina Faso. BMC Med Ethics. 2014;15:13.

34. Ravinetto R, Alirol E, Mahendradhata Y, Rijal S, Lutumba P, Sacko M, et al. Clinical Research in Neglected Tropical Diseases: The Challenge of Implementing Good Clinical (Laboratory) Practices. PLoS Negl Trop Dis. 2016;10:6.

35. INSD-EPOB. Enumération de la population de Ouagadougou et de Bobo-Dioulasso. Ouagadougou; 2012.

36. PNGT. Diagnostic conjoint du village de Bana. Bobo-Dioulasso; 2002.

37. Olivier de Sardan J-P. La rigueur du qualitatif: les contraintes empiriques de l'interprétation socioanthropologique. Academia-B. Academia-Bruylant, editor. 2008.

38. Paille P, Muchielli A. L'analyse qualitative en sciences humaines et sociales. 4th ed. Armand Colin 2016, editor. 2016. 
39. Albarello L. Apprendre à chercher: l'acteur social et la recherche scientifique (2ème édition). (Bruxelles) DBU, editor. 2007.

40. Fienieg B, Nierkens V, Tonkens E, Plochg T, Stronks K. Why play an active role? A qualitative examination of lay citizens' main motives for participation in health promotion. Health Promot Int. 2012;27:416-426.

41. Stunkel L, Grady C. More than the money: A review of the literature examining healthy volunteer motivations. Contemp Clin Trials. Elsevier; 2011;32:342-52.

42. Masiye F, Kass N, Hyder A, Ndebele P, Mfutso-Bengo J. Why mothers choose to enrol their children in malaria clinical studies and the involvement of relatives in decision making: Evidence from Malawi. Malawi Med J. 2008;20:50-6.

43. Clary EG, Snyder M, Ridge RD, Copeland J, Stukas AA, Haugen J, et al. Understanding and assessing the motivations of volunteers: A functional approach. J. Pers. Soc. Psychol. US: American Psychological Association; 1998. p. 1516-30.

44. Boz I, Palaz S. Factors Influencing the Motivation of Turkey's Community Volunteers. Nonprofit Volunt Sect Q. SAGE Publications Inc; 2007;36:643-61.

45. Snyder M, Omoto AM, Crain AL. Punished for their Good Deeds: Stigmatization of AIDS Volunteers. Am Behav Sci. SAGE Publications Inc; 1999;42:1175-92.

46. Kiemde F, Bonko M dit A, Tahita MC, Lompo P, Tinto H, Mens PF, et al. Can clinical signs or symptoms combined with basic hematology data be used to predict the presence of bacterial infections in febrile children under 5 years? BMC Pediatr. 2018;18.

47. Swetlitz I. For the first time, researchers will release genetically engineered mosquitoes in Africa. STAT Med Biotech [Internet]. 2018; Available from: https://www.statnews.com/2018/09/05/releasegenetically-engineered-mosquitoes-africa/

48. Barry A. Lâchage de moustiques transgéniques: Target malaria, un «remède» redouté. Sidwaya, Le Quotid burkinabé d'information [Internet]. Burkina Faso; 2018 Dec; Available from: https://www.sidwaya.info/blog/2018/12/19/lachage-de-moustiques-transgeniques-target-malariaun-remede-redoute/

49. Laabes EP, Desai R, Zawedde SM, Glew RH. How much longer will Africa have to depend on western nations for support of its capacity-building efforts for biomedical research? Trop Med Int Heal. 2011;16:258-62.

50. Edejer TTT. North-South research partnerships: The ethics of carrying out research in developing countries. Br Med J. 1999;319:438-441.

51. Chu KM, Jayaraman S, Kyamanywa P, Ntakiyiruta G. Building Research Capacity in Africa: Equity and Global Health Collaborations. PLoS Med. Public Library of Science (PLoS); 2014;11:e1001612.

52. Massawe IS, Lusingu JP, Manongi RN. Community perception on biomedical research: A case study of malariometric survey in Korogwe District, Tanga Region, Tanzania. BMC Public Health. 2014;14:385. 
53. Liheluka EA, Lusingu JP, Manongi RN. Community perceptions on the secondary health benefits established by malaria vaccine trials (RTS,S phase 2 and phase 3 ) at the Korogwe site in North Eastern Tanzania. Malar J. 2013;12:157.

\section{Declarations}

\section{Ethics approval and consent to participate}

This study was part of a project which aimed to eradicate malaria through the development of innovative technology for the vector control by using genetic modification of the few specific strains of the Anopheles mosquito that transmit the disease. In Burkina Faso, the project received approval from the local institutional ethics committee (Centre Muraz Institutional Ethics Committee), reference number 0092012/CE-CM.

\section{Consent to publication}

Not applicable

\section{Availability of data and material}

The datasets generated and/or analysed during the current study are not publicly available due to the fact that they are part of a bigger research project that is still ongoing; but are available from the corresponding author on reasonable request.

\section{Competing interests}

The authors declare that there is a competing interests, because data were collected and analyzed by the member of Target Malaria in Burkina Faso.

\section{Funding}

Authors, except $\mathrm{JL}$ and PT, received funding from Target Malaria, which received core funding from the Bill \& Melinda Gates Foundation and from the Open Philanthropy Project Fund, an advised fund of Silicon Valley Community Foundation. These funding bodies have had no direct role in the design of the study nor in the collection, analysis, interpretation of data and in the writing of the manuscript.

\section{Authors' contributions}

NB led the study design, data collection, analysis, interpretation of the results and drafting of the manuscript. NB oversaw the manuscript with inputs from PT, LPT, JL, MD, RKD and AD. All authors read and approved the final manuscript.

\section{Acknowledgements}


We are grateful to the communities of Bana in which this study was conducted, for being gracious enough to allow us to ask them questions. We thank Dr Karen E. Logan from Imperial College of London; Dr Charles Guissou from Institut de Recherche en Sciences de la Santé (IRSS) in Burkina Faso; Dr Valentina Cisnetto-Brauch from Imperial College of London and Delphine Thizy from Imperial College of London for their support and assistance to review the manuscript and for all their contributions. Last but not least, we very grateful for all the participants to the interview and focus group discussions.

\section{Figures}

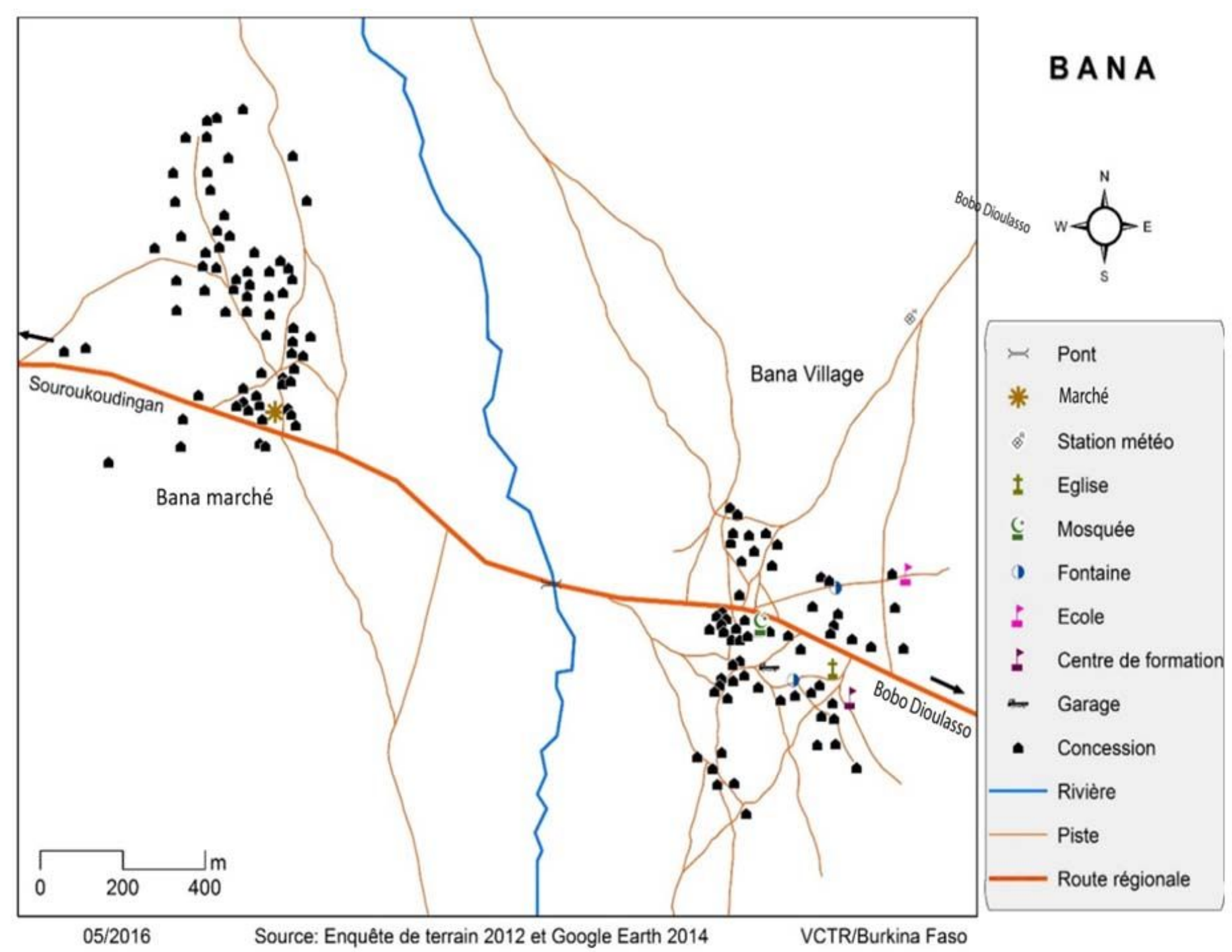

Figure 1

The location map of the village and the distribution of the area's inhabitants 


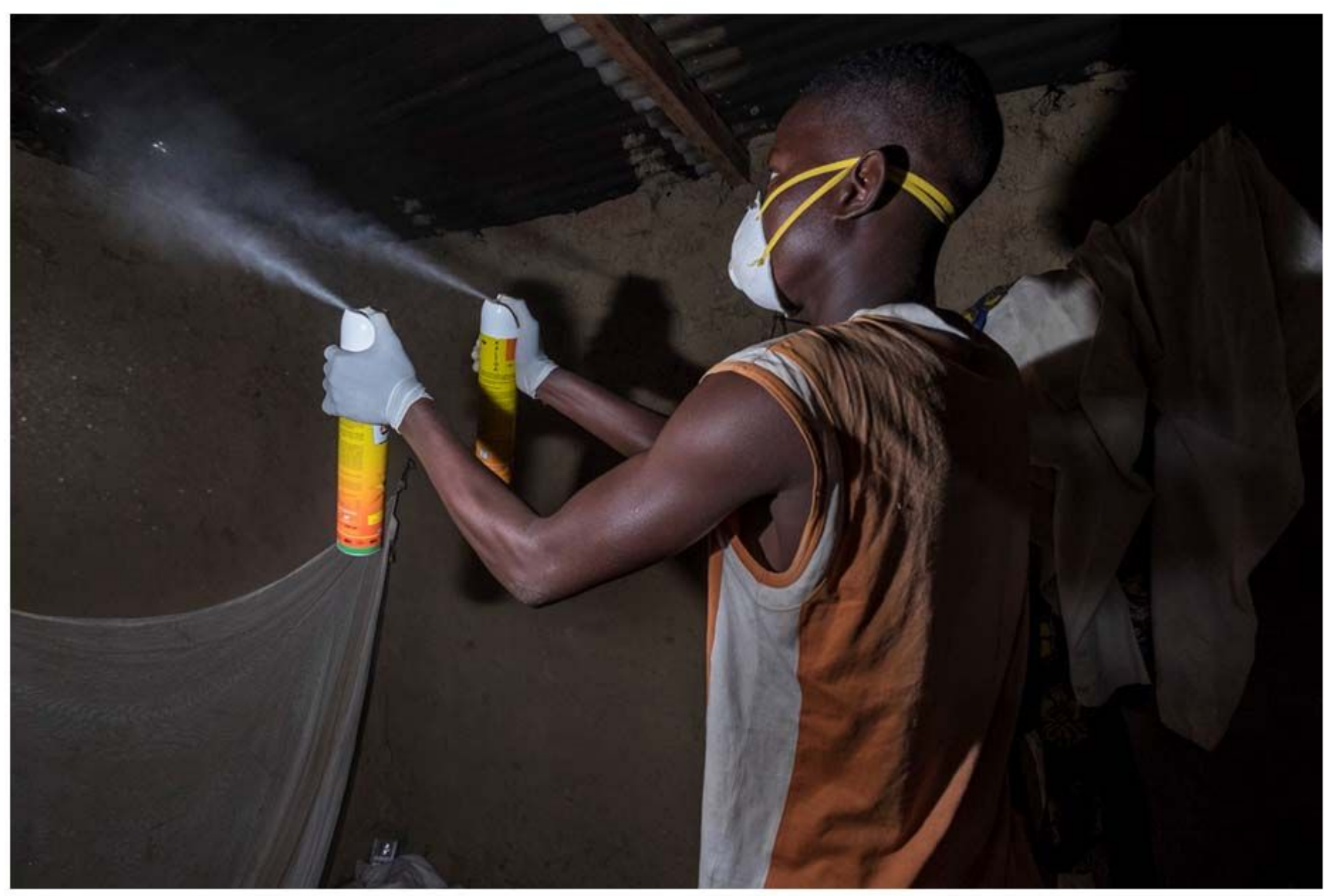

Figure 2

Spraying activity 


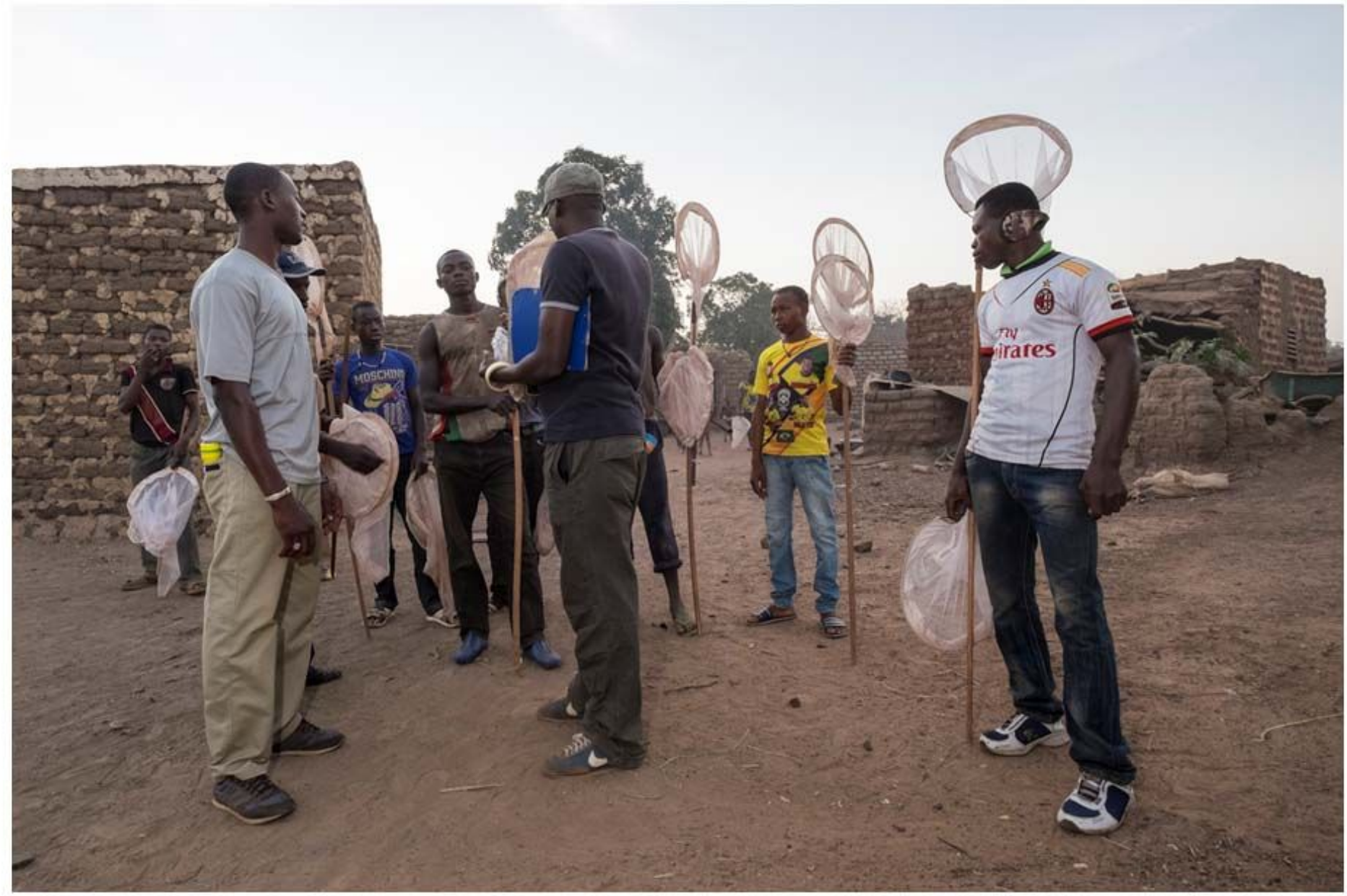

Figure 3

Session of preparation and setting up of mosquito collector 


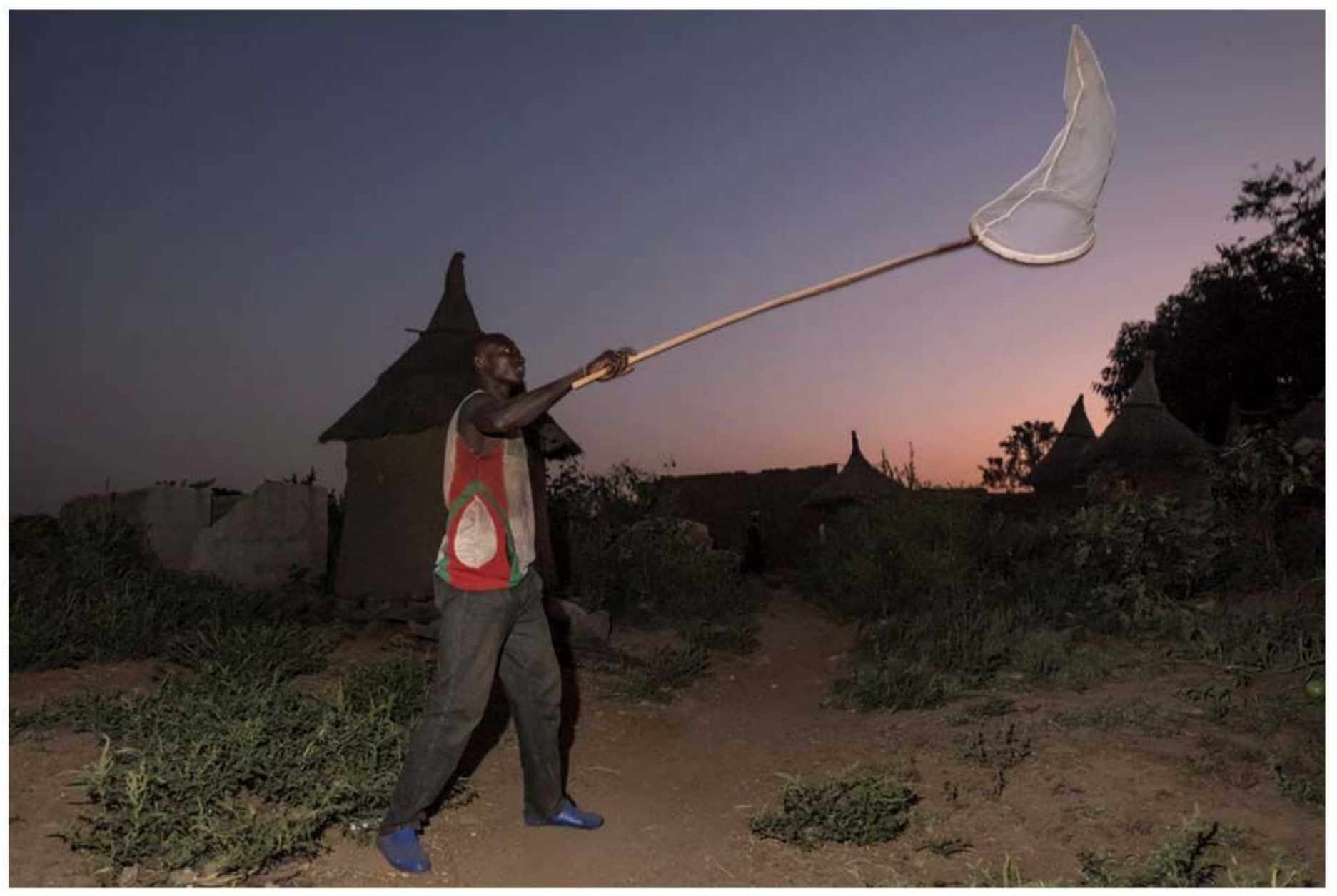

Figure 4

A collector of mosquito swarms in the village of Bana 